\title{
Hedera helix L. Türünün Sürünücü ve Tırmanıcı Kısımlarında Bazı Pigment ve Antosiyanin İçeriklerinin Karşılaştırılması
}

\author{
Emire ELMAS ${ }^{1 *}$, Sevda TÜRKIȘ ${ }^{2}$ \\ ${ }^{1}$ Sinop Üniversitesi, Fen-Edebiyat Fakültesi, Biyoloji Bölümü, Sinop \\ ${ }^{2}$ Ordu Üniversitesi, Eğitim Fakültesi, Matematik ve Fen Bilgisi Ĕ̈itimi Bölümü, Ordu \\ (ORCID: 0000-0002-5620-1798) (ORCID: 0000-0002-1853-8437)
}

\begin{abstract}
$\ddot{O} \mathbf{z}$
Hedera helix L. yaprak döken orman ekosistemlerinin önemli türlerinden birisidir. Yenice Ormanları'nda bulunan Kavaklı Tabiatı Koruma Alanı’nda tırmanıcı özelliğinin dışında yoğun bir yer örtücü (sürünücü) özellik de sergilemektedir. Bu çalışmada, Kavaklı Tabiatı Koruma Alanı'nda yayılış gösteren $H$. helix türünün sürünücü ve tırmanıcı kısımlarının yaprak ve gövdelerinde bazı bitki pigmentleri (klorofil-a, klorofil-b, Kl-a/Kl-b, karotenoid ve antosiyanin) açısından fark olup olmadığının araştırılması amaçlanmıştır. Üç farklı bitki bireyinden yaprak ve gövde örnekleri toplanmış ve $1 \mathrm{~g}$ taze örnek kullanılarak ekstraksyon işlemi yapılmıştır. Klorofiller için 645,662 nm ve karotenoid için $470 \mathrm{~nm}$ 'deki absorbanslar ölçülmüştür. Antosiyanin miktarını belirlemek için $1 \mathrm{~g}$ yaprak örneği $12 \mathrm{ml}$ metanol/HCl $(99 / 1)$ içerisinde 24 saat $+4{ }^{0} \mathrm{C}^{\prime}$ de inkübe edilerek 530 ile $657 \mathrm{~nm}$ 'deki absorbanslar ölçülmüştür. Sonuçların değerlendirilmesinde tek yönlü varyans analizi (ANOVA) ve Tukey testi kullanılmıştır. Buna göre, sürünücü ve tırmanıcı bitki kısımlarının yaprak ve gövdeleri arasında Kla, Klb, Kla/Klb ve karotenoid içerikleri açısından istatistiksel olarak bir farklılık bulunmamıştır. Antosiyanin içeriği açısından farklı bitki kısımlarına ait gövdeler arasında önemli bir farklılık bulunmazken, tırmanıcı kısımlardaki yapraklarda sürünücü kısımların yapraklarına göre anlamlı düzeyde daha yüksek olduğu tespit edilmiştir $(\mathrm{P}<0,05)$. Elde edilen bulgular, yaprak döken orman ekosistemlerinde farklı orman katlarında bulunan $H$. helix türünün hem sürünücü formda hem de tırmanıcı formda biyomas ve oksijen üretimi açısından benzer etkililikte katkı sağladığını göstermektedir.
\end{abstract}

Anahtar kelimeler: Hedera helix, klorofil, karotenoid, antosiyanin, Kavaklı TKA.

\section{Comparison of Some Pigment Quantities in Hedera helix L. Leaves of Creeping and Climbing Plant Parts}

\begin{abstract}
Hedera helix L. is an important species in forest ecosystems. In Kavaklı Nature Reserve Area of the Yenice Forest, it exhibits both climbing and ground covering (prostrating) behavior. In this study, it was aimed to investigate the differences of some plant pigments (chlorophyll-a, chlorophyll-b, Chl-a/Chl-b, carotenoid and anthocyanin) between leaves and stems on creeping and climbing parts of $H$. helix. Leaf and stem samples were collected from 3 different plant individuals. The extraction was made by using $1 \mathrm{~g}$ sample for chlorophylls and carotenoid. The absorbances were measured in 662 and $645 \mathrm{~nm}$ for chlorophylls and in $470 \mathrm{~nm}$ for carotenoids. To determine anthocyanin content, $1 \mathrm{~g}$ sample was incubated in $12 \mathrm{ml}$ methanol/ $\mathrm{HCl}(99 / 1)$ at $+4{ }^{0} \mathrm{C}$ for $24 \mathrm{~h}$. Then, the absorbances in 530 and $657 \mathrm{~nm}$ were measured. One-way analysis of variance (ANOVA) and Tukey Test were used to evaluate the results. According the results, there were no differences in $\mathrm{Cl}-\mathrm{a}, \mathrm{Cl}-\mathrm{b}, \mathrm{Cl}-\mathrm{a} / \mathrm{Cl}-\mathrm{b}$ and carotenoid contents between leaves and stems of creeping and climbing parts. Anthocyanin contents were significantly higher in leaves of climbing part then ones of creeping part $(\mathrm{P}<0.05)$, although there was no significant differences between stems of different parts of $H$. helix. The results show that $H$. helix that found in different forest layers in deciduous forest ecosystems contributes in similar effectiveness in both creeping and climbing form in terms of biomass and oxygen production.
\end{abstract}

Keywords: Hedera helix, chlorophyll, carotenoid, anthocyanin, Kavaklı NRA.

*Sorumlu yazar: eelmas@sinop.edu.tr

Geliş Tarihi: 25.05.2018, Kabul Tarihi: 21.04.2019 


\section{Giriş}

Araliaceae familyasına ait olan ve her dem yeşil bir karaktere sahip olan Hedera helix L. türü, çok yıllık odunsu bir bitkidir. Orman ekosistemlerinin önemli bir türü olarak 0-1500 m yükseltiler arasında yayılış göstermekte ve $30 \mathrm{~m}$ yüksekliğe kadar boylanabilmektedir. Hem sürünücü hem de tırmanıcı bir yapı gösteren bu türün yaprakları basit yapıda olup, tüysüzdür ve alternat dizilim gösterir [1]. Yaz sonlarında açık yeşi1/sarı olan yapraklar, kışın mor renge dönüşmektedir [2]. H. helix türü özellikle çok eski ormanlık alanlar ile sekonder ormanlık alanların çoğunda yerleşim göstermektedir. Ayrıca, 1lıman koşulların indikatörü olarak da kabul edilmektedir [3]. Gölgelik koşullara toleransı yüksek olan bu tür, özellikle verimli topraklara sahip ormanlık alanların zemin katmanında dominant hale gelmektedir [2, 4]. H. helix gibi kök tırmanıcıları, genelde çapı geniş olan ve pürüzlü gövde kabuğuna sahip ağaçları tercih etmektedirler [5]. Güçlü kanopiye sahip olan ağaç türleri her ne kadar $H$. helix türünün büyümesini bir miktar sınırlasa da, Fraxinus excelsior, Quercus robur ve Acer campestre gibi türler bu sarmaş1k türünün kanopide büyümesini sağlayacak kadar ışığa olanak tanımaktadırlar. Böylece özellikle kanopisi yoğun olmayan ağaç türlerinin olduğu alanlarda $H$. helix türü sabit bir tür olarak yayılış göstermektedir [2].

Karabük il sınırları içerisinde yer alan Kavaklı Tabiatı Koruma Alanı, Türkiye'nin 9 sıcak noktasından biri olan Yenice Ormanları'nın bir parçasıdır ve bu alan, özellikle odunsu türler açısından zengin çeşitliliğe sahiptir. Bu bölgede H. helix türü 800-1000 m'ler arasında Fagus orientalis-Carpinus betulus kommunitesinin ve 1200-1300 m'ler arasinda Abies nordmanniana subsp. equi-trojani kommunitesinin önemli bileşenlerinden biridir. Kavaklı Tabiatı Koruma Alanı'nda hem tırmanıcı hem de sürünücü olarak yer yer yoğun yayılış göstermektedir. $H$. helix türü, ekosistemde farklı vejetasyon katlarında yayılış göstermesinin bir sonucu olarak, mutant ve yabanıl tip hücrelerin karışımına sahiptir. Böylece dimorfik yapraklar oluşturan bir kimera bitkisi özelliği taşımaktadır [6, 7].

Orman ekosistemleri ekolojik koşullar açısından heterojen çevre koşullarına sahiptir ve en büyük kısıtlayıcı faktörlerden birisi ışık elde edilebilirliğidir. Bu çalışma kapsamında, $H$. helix türünün aynı gelişim fazında olan fakat orman ekosisteminde farklı katmanlarda bulunan sürünücü ve tırmanıcı kısımlarının gövde ve yapraklarında Kla, $\mathrm{Klb}, \mathrm{Kla} / \mathrm{Klb}$, karotenoid ve antosiyanin içerikleri açısından fark olup olmadığının araştırılması planlanmıştır.

\section{Materyal ve Metot}

Kavaklı Tabiatı Koruma Alanı'nda yayılış gösteren üç farklı H. helix (Şekil 1) bireyinin sürünücü formundaki kısımları ile ağaç gövdesi üzerinde tırmanıcı kısımlarından Haziran 2015 tarihinde yaprak ve gövde örnekleri alınmıştır. Nemli kağıtlara sarılan örnekler laboratuvara getirilene kadar serin bir ortamda siyah poşetler içinde muhafaza edilmiştir. Laboratuvara getirilen örneklerden $1 \mathrm{~g}$ taze yaprak ve gövde örneği kullanılarak De Kok ve Graham [8] yöntemine göre ekstraksyon işlemi yapılmış ve klorofil içerikleri için $662 \mathrm{~nm}, 645 \mathrm{~nm}$ ve karotenoid için $470 \mathrm{~nm}$ 'deki absorbanslar ölçülmüştür [8]. Pigment konsantrasyonları Lichtentaler ve Welburn [9]'e göre hesaplanmıştır.

Antosiyanin miktarını belirlemek için $1 \mathrm{~g}$ yaprak örneği $12 \mathrm{ml}$ metanol/ $\mathrm{HCl}(99 / 1)$ içerisinde 48 saat $+4{ }^{0} \mathrm{C}^{\prime}$ de inkübe edilerek 530 ile $657 \mathrm{~nm}$ 'deki absorbanslar ölçülmüştür. Antosiyanin konsantrasyonları $\mathrm{A}=\mathrm{A}_{530}-\mathrm{A}_{657} / 3$ formülü kullanılarak hesaplanmıştır $[10,11]$. Elde edilen farklıl1kların istatistiksel olarak önemli olup olmadığı SPSS v20 paket programı kullanılarak tek yönlü varyans analizi (ANOVA) ve Tukey testi aracılığ ile değerlendirilmiştir. 


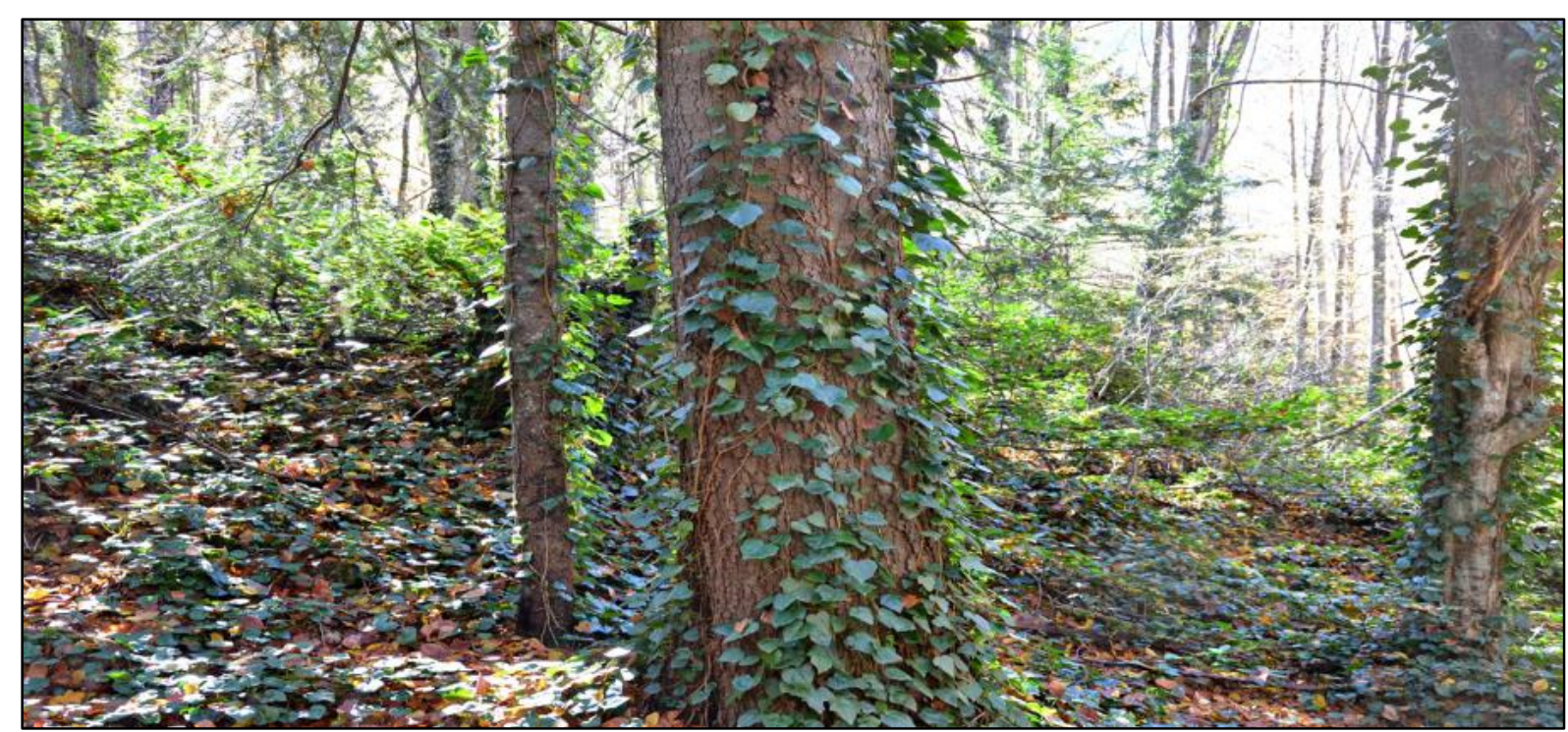

Şekil 1. Kavaklı Tabiatı Koruma Alanı'nda Hedera helix türünün görünümü

\section{Bulgular ve Tartışma}

Laboratuvar analizleri sonucunda elde edilen sonuçlar Tablo 1'de verilmiştir. $H$. helix türünün tırmanıcı kısımlarındaki yaprak ve gövdelerinde $\mathrm{Kla}, \mathrm{Klb}, \mathrm{Kla} / \mathrm{Klb}$, karotenoid ve antosiyanin oranları daha yüksek bulunmuştur. Kla/Klb oranlarının ise sürünücü formdaki bitki kısımlarının yaprak ve gövdelerinde daha yüksek olduğu tespit edilmiştir. İstatistiksel analizlere göre, sürünücü bitki kısımlarındaki yaprak ve gövdeler ile tırmanıcı formdaki bitki kısımlarının yaprak ve gövdeleri arasında klorofil ve karotenoid içerikleri açısından tespit edilen bu farklılıklar önemli bulunmamıştır ( $\mathrm{P}>0,05$; Tablo 2). Bunun yanında, antosiyanin içeriğinin tırmanıcı kısımlara ait yapraklarda sürünücü kısımlardaki yapraklardan istatistiksel olarak anlamlı düzeyde daha yüksek olduğu tespit edilmiştir ( $\mathrm{P}<0,05$; Tablo 2). Her iki formun gövdelerinde antosiyanin içeriği açısından belirlenen farklılık istatistiksel olarak önemli değildir.

Tablo 1. Ölçümü yapılan pigmentlerin ortalama ve standart sapma değerleri

(S: Sürünücü kısımlara ait; A: Ağaç gövdesi üzerinde tırmanıcı kısımlara ait)

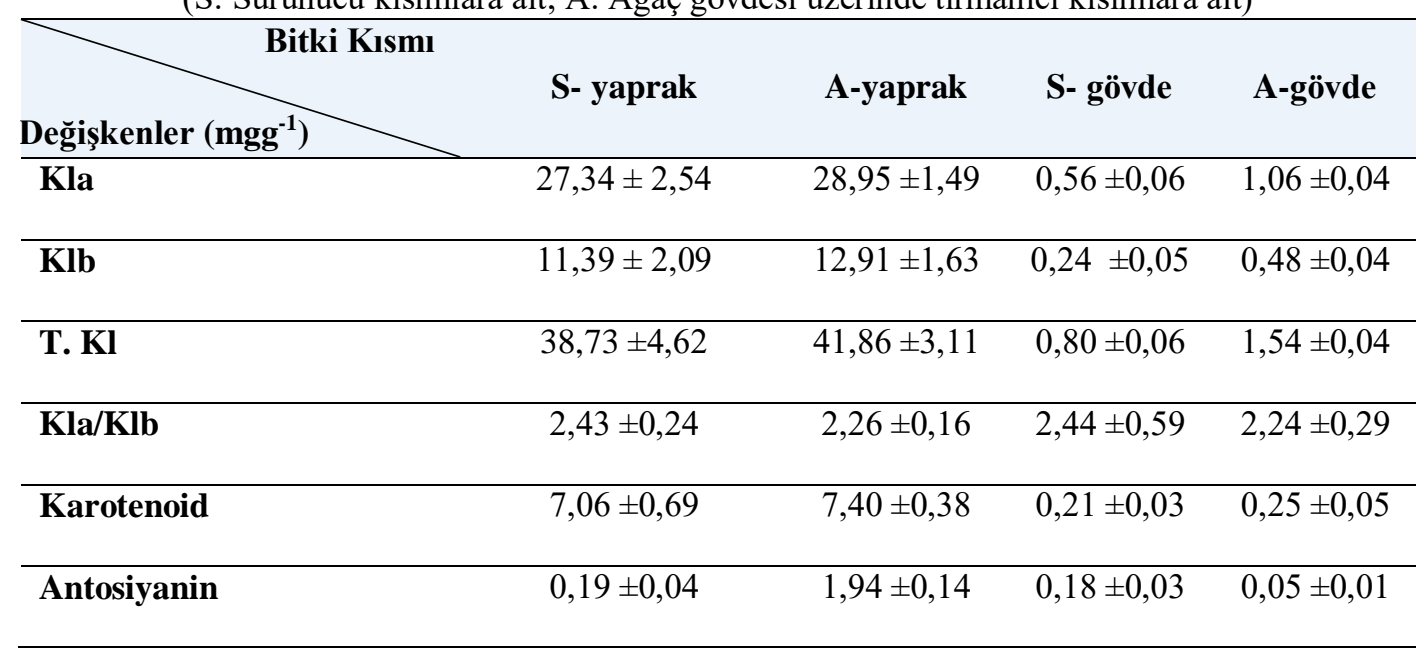


Tablo 2. Hedera helix türünde sürünücü ve tırmanıcı kısımlara ait yaprak ve gövdelerin bazı pigment ve antosiyanin içerikleri açısından farklılıklarını gösteren TUKEY analiz sonuçları (S: Sürünücü kısımlara ait; A: A ğaç gövdesi üzerinde tırmanıcı kısımlara ait)

\begin{tabular}{llllll}
\hline Bağımlı & Bitki Kısmı & & Ortalama fark (I-J) & St. Hata & Önemlilik \\
\hline Kla & S-Yaprak & A-yaprak & $-1,61$ & 1,20 & 0.75 \\
& S-Gövde & A-gövde & $-0,50$ & 1,20 & 0.87 \\
\hline Klb & S-Yaprak & A-yaprak & $-1,52$ & 1,08 & 0.62 \\
& S-Gövde & A-gövde & $-0,24$ & 1,08 & 0.94 \\
\hline T.Kl & S-Yaprak & A-yaprak & $-3,13$ & 2,27 & 0.68 \\
& S-Gövde & A-gövde & $-0,74$ & 2,27 & 0.90 \\
\hline Kla/Klb & S-Yaprak & A-yaprak & 0,17 & 0,29 & 0.94 \\
& S-Gövde & A-gövde & 0,20 & 0,29 & 0.72 \\
\hline Karotenoid & S-Yaprak & A-yaprak & $-0,34$ & 0,32 & 0.84 \\
& S-Gövde & A-gövde & $-0,05$ & 0,32 & 0.97 \\
\hline Antosiyanin & S-Yaprak & A-yaprak & $-1,75$ & 0,06 & $\mathbf{0 . 0 0 *}$ \\
& S-Gövde & A-gövde & 0,13 & 0,06 & 1.00 \\
\hline
\end{tabular}

*: $P<0.05$ düzeyinde önemlidir.

Bitkilerin gelişimi süresince boyut ve komplekslikte artış olur ve yaşam evrelerini tamamlayana kadar vejetatif ve reprodüktif olmak üzere fizyolojik olarak birbirinden farkl1lık gösteren iki faz geçirirler. Vejetatif ile reprodüktif gelişim fazları arasında kalan süreç ise geçiş fazı olarak adlandırılmaktadır [12]. Hedera helix türü, üreme olgunluğuna erişmiş kısımlardaki yapraklar ile jüvenil kısımdaki yapraklarda heteromorfizm sergileyen bir türdür ve üreme olgunluğuna erişen kısımlardaki yapraklar jüvenil kısımlardakinden fizyolojik olarak çeşitli farklılıklar gösterir [13, 14]. Bu çalışmada materyal olarak kullanılan bitki kısımlarında yapraklar açısından morfolojik olarak bir farklılık bulunmamaktadır. Fakat orman yapısı içerisinde hem sürünücü hem de tırmanıcı olarak farklı habitatlarda varlık göstermektedir. Yoğun orman dokusundan ötürü, sürünücü formda olan kısımları daha yoğun gölge koşullarına maruz kalmaktadır. Bitki türlerinin gölge koşullarında besin dengelerini sürdürebilme yetenekleri değişkenlik göstermektedir [15]. Bu nedenle farklı fiziksel koşullara maruz kalan bu iki bitki kısmı arasında bazı pigmentler ve antosiyanin içeriği bakımından farklılık olup olmadığ 1 araştırılmıştır.

Gelişim süreci boyunca bitkilerin bazı özellikleri kademeli olarak değişirken, bazı özellikleri hızlı bir değişim geçirir. Bununla birlikte, büyüme ve farklılaşma, sinyal yolları aracıllı̆ıyla birbiriyle koordineli olarak devam eder [16]. Bitkiler, ş̧ık yoğunluğu, tipi ve besin elde edilebilirliği gibi çevresel faktörlerin de etkisiyle yaşamları süresince, genetik kapasitelerinin elverdiği ölçüde farklı tiplerde yapraklar üretme kapasitesine sahiptirler. Bu farklılık şekilsel olduğu kadar fizyolojik olarak da belirginleşebilmektedir [17]. Gelişim dönemine göre yapraklardaki pigment miktarı farklılık gösterebilmektedir [18, 19]. Fakat bu çalışmada, H. helix türünün sürünücü ya da tırmanıcı kısımları arasında klorofil a, klorofil b ve karotenoid pigmentlerinin içeriği bakımından anlamlı bir farklılık tespit edilmemiştir. Bu durum aynı gelişim dönemine ait yapraklarda 1şıklanma farklılığına rağmen fotosentez aktivitesinin benzer olduğunu göstermektedir. Bauer ve Bauer [20] tarafindan yapılan çalışmada da $H$. helix türünün jüvenil ve olgun yaprakları arasında klorofil açısından bir farklılık belirlenmemiştir. $\mathrm{Bu}$ sonuçlar $H$. helix türünün gölge koşullarına adaptasyon konusunda sahip olduğu yüksek plastisite özelliği [2] ile açıklanabilir. Ek olarak, büyük ağaç kitlelerinin olduğu alanlarda, 1şık koşullarının uygunluğuna göre $H$. helix türü kanopi altında daha iyi gelişim gösterebilmektedir. Bu durum alanda mevcut olan ağaç türlerine bağlı olarak değişkenlik göstermektedir [21]. Konak bitkilerin kabuk yapısı ve atraktif özellikleri $H$. helix türünün yer örtücü olarak bulunma yüzdesini etkilemektedir. Carpinus 
betulus ve Fraxinus excelsisor gibi genç büyüme evrelerinde çataklı kabuk yapısına sahip olan türler, H. helix için iyi konak bitkiler olma özelliği gösterirken, Fagus sylvatica ve Taxus baccata gibi türlerinin atraktif özelliği daha zayıf olmaktadır. Ayrıca alan içindeki odunsu tür kompoziyonu, ağaç gövde çapı ve toprak yapısı da tırmanıcı türlerin çeşitliliğini ve özelliklerini etkilemektedir [21, 22]. Kavaklı Tabiatı Koruma Alanı'nda gövde çapı yüksek ağaçsı tür sayısının fazla olmasının yanında, Fagus orientalis türü de örtüşü en yüksek türler arasında yer almaktadır. Bu durum da $H$. helix türünün bu alanda yoğun yer örtücü olma özelliğini açıklamaktadır. Kanopi altında iyi gelişme olanağı bulması klorofil a, klorofil b ve karotenoid pigmentlerinin içeriği bakımından tırmanıcı kısımlarla fark olmamasını açıklayabilecek nedenler arasında yer almaktadır.

Diğer yandan tırmanıcı kısımlarda bulunan yaprakların antosiyanin içeriğinin sürünücü kısımlardakinden daha yüksek olduğu belirlenmiştir. Antosiyanin, aşırı 1şık, düşük sıcaklık, enfeksiyon veya besin eksikliği gibi koşullarda, bitki dokularını oksidatif stresten koruyan en güçlü antioksidanlardan biridir [23]. H. helix türünün dokularında antosiyanin birikimi, faza bağımlı bir süreçtir ve olgun fazda dihidrofenol 4-redüktaz enzim aktivitesinin eksikliğine bağlı olarak olgun dokularda biriktirilememektedir [13]. Juvenil ve olgun fazdaki bitki kısımlarının antosiyanin içeriklerinde Muray ve Hackett [13] tarafından tespit edilmiş farklılıklara ek olarak, juvenil fazdaki kısımlarda da bitki kısımlarının bulundukları yere göre antosiyanin içeriği açısından farklılık görüldüğü tespit edilmiştir. Çalışmamızda, ikisi de jüvenil faza ait yapraklar olmalarına rağmen, ağaç gövdesi üzerindeki bitki kısımlarında yer alan yaprakların antosiyanin içeriğinin sürünücü kısımlardaki yapraklardan anlamlı düzeyde daha yüksek olduğu tespit edilmiştir. Bu durum 1şığın etkisinin artmaya başlamasıyla birlikte, antosiyanin birikiminin de artmaya başladığını göstermektedir. Bu sonuç, ışığın antosiyanin üretimine olan etkisiyle ilgili başka çalışmalarda da gösterilmiştir ve antosiyaninin fotosentetik yapıların korunmasındaki rolü ile açıklanmaktadır [24, 25].

\section{Sonuç ve Öneriler}

Elde edilen sonuçlar $H$. helix türünün sürünücü ya da tırmanıcı kısımlarda yer alan ve aynı gelişim fazına ait bitki kısımlarının orman ekosistemi içerisinde farklı katmanları işgal ettikleri halde biyomas ve oksijen üretimi açısından benzer etkililikte katkı sağladığını göstermektedir. Bu durum, aynı bitki yapısındaki farklı ekolojik faktörlere maruz kalan dokuların farklı fizikokimyasal cevaplarının göstergesidir. H. helix, yaprak döken orman ekosistemlerinin önemli türlerinden birisi olmasının yanı sıra, peyzaj çalışmalarında da yaygın olarak kullanılan bir bitki türüdür. Bu nedenle ekofizyolojisinin anlaşılması, hem orman ekosistemlerinde türlerin nişlerinin daha iyi anlaşılması hem de etkili peyzaj uygulamalarının yapılmasına katkı sağlayacaktır. Bu çalışmada, ağaç boylarının çok yüksek olması ve ağaçların tepe kısmından örnekleme yapılması için gerekli teçhizat bulunmaması nedeniyle, $H$. helix türünün ağacın taç bölümünde yer alan kısımlarından örnek alınamamıştır. Bu nedenle, H. helix türünün ağaçların tepe kısımlarında bulunan yaprak ve gövdelerinin de dahil edilerek yapılacak yeni çalışmaların bu konuya katkı sağlayacağı düşünülmektedir.

\section{Teşekkür}

Bu çalışma TÜBİTAK tarafindan desteklenen $113 Z 820$ No.lu proje kapsamında gerçekleştirilmiştir.

\section{Kaynaklar}

[1] Chamberlain D.F. 1972. Hedera L. in Flora of Turkey and the East Aegean Islands, Edited by Davis P.H., Vol.4, Edinburgh: Edinburgh Univ Press, 538-539.

[2] Metcalfe D.J. 2005. Hedera helix L. Journal of Ecology,93 (3): 632-648.

[3] Ellenberg H. 1988. Vegetation Ecology of Central Europe. Cambridge University Press, 731s. Cambridge, UK.

[4] Sack L., Grubb P.J. 2002. The combined impacts of deep shade and drought on the growth and biomass allocation of shade-tolerant woody seedlings. Oecologia, 131: 175-185. 
[5] Castagneri D., Garbarino M., Nola P. 2013. Host preference and growth patterns of ivy (Hedera helix L.) in a temperate alluvial forest. Plant Ecology,214 (1): 1-9.

[6] Rogers S.O., Bonnett H.T. 1989. Evidence for apical initial cells in the vegetative shoot apex of Hedera helix cv. Goldheart. American Journal of Botany,76 (4): 539-545.

[7] Scheres B. 2001. Plant cell identity. The role of position and lineage. Plant Physiology,125 (1): 112-114.

[8] De Kok L.J., Graham M. 1989. Level of pigments, soluble proteins, amino acids and sulfhydryl compounds in foliar tissue of Arabidopsis thaliano during dark-induced and natural senescence. Plant Physiology and Biochemistry, 27: 203-209.

[9] Lichtenthaler H.K., Wellburn A.R. 1983. Determination of total carotenoids and chlorophylls a and $b$ of leaf extracts in different solvents. Biochemical Society Transaction, 11: 591-592.

[10] Mancinelli A.L., Yang C.P.H., Lindquist P., Anderson O.R., Rabino I. 1975. Photocontrol of anthocyanin synthesis: III. The action of streptomycin on the synthesis of chlorophyll and anthocyanin. Plant Physiology,55 (2): 251-257.

[11] Reay F.P., Fletcher R.H., Thomas V.J.G. 1998. Chlorophylls, carotenoids and anthocyanin concentrations in the skin of 'Gala' apples during maturation and the influence of foliar applications of nitrogen and magnesium. Journal of the Science of Food Agriculture, 76: 63-71.

[12] Biggerstaff M.S., Beck C.W. 2007. Effects of English ivy (Hedera helix) on seed bank formation and germination. The American Midland Naturalist, 157: 250-257.

[13] Murray J.R., Hacket W.P. 1991. Dihydroflavonol reductase activity in relation to differential anthocyanin accumulation in juvenile and mature phase Hedera helix L. Plant Physiology, 97: 343-351.

[14] Murray J.R., Smith A.G., Hackett W.P. 1994. Differential dihydroflavonol reductase transcription and anthocyanin pigmentation in the juvenile and mature phases of ivy (Hedera helix L.). Planta, 194: 102-109.

[15] Dale M.P., Causton D.R. 1992. Use of the chlorophyll a/b ratio as a bioassay for the light environment of a plant. Functional Ecology, 80 (3): 190-196.

[16] Poethig R.S. 2003. Phase change and the regulation of developmental timing in plants. Science,301 (5631): 334-336.

[17] Kerstetter R.A., Poethig R.S. 1998. The specification of leaf identity during shoot development. Annual Review of Cell and Developmental Biology, 14 (1): 373-398.

[18] Hutchison K.W., Sherman C.D., Weber J., Smith S.S., Singer P.B., Greenwood M.S. 1990. Maturation in larch. II. Effects of age on photosynthesis and gene expression in developing foliage. Plant Physiology, 94: 1308-1315.

[19] Cevahir C., Yentür S., Yazgan M., Ünal M., Yılmazer N. 2004. Peroxidase activity in relation to anthocyanin and chlorophyll content in juvenile and adult leaves of "mini-star" Gazania splendens. Pakistan Journal of Botany, 36 (3): 603-609.

[20] Bauer H., Bauer U. 1980. Photosynthesis in leaves of the juvenile and adult phase of ivy (Hedera helix). Physiologia Plantarum, 49 (4): 366-372.

[21] Mănescu C.R., Buda C., Toma F., Petra S. 2018. Studies on growth and development of Hedera helix L. on different woody species. Scientific Papers Series B Horticulture, 63: 597-600.

[22] Leicht-Young S.A., Pavlovic N.B., Frohnapple K.J., Grundel R. 2010. Liana habitat and host preferences in northern temperate forests. Forest Ecology and Management, 260: 1467-1477

[23] Grace S.C. 2005. Phenolics as antioxidants. in Antioxidants and Reactive Oxygen Species in Plants, Edited by Smirnoff N., Blackwell Publishing Ltd, UK, 141-168.

[24] Trojak M., Skowron E. 2017. Role of anthocyanins in high-light stress response. World Scientific News, 81 (2): 150-168.

[25] Narbona E., Jaca J., Del Valle J.C., Valladares F., Buide M.L. 2018. Whole-plant reddening in Silene germana is due to anthocyanin accumulation in response to visible light. Plant Biology, 20 (6): 968-977. 